О. В. Лапицкая

Гомельский государственный технический университет имени П. О. Сухого

\title{
ОСОБЕННОСТИ ЛЕСОПОЛЬЗОВАНИЯ РЕСПУБЛИКИ БЕЛАРУСЬ В СИСТЕМЕ УСТОЙЧИВОГО РАЗВИТИЯ
}

Показано, что система управления лесным хозяйством в Беларуси развивалась, начиная c XV в. В средние века основными ресурсами леса считалась продукция, полученная от охоты и бортничества. Отмечено, что организованное лесное хозяйство в Беларуси появилось позже, чем в Западной Европе, но раньше, чем в России. Древесина как основной ресурс леса стала доминировать, начиная с конца XVIII в. Вырубка древесины привела к уменьшению лесистости территории Беларуси до $33 \%$ в 1913 г. и до 22\% в 1918 г. В работе приведены достоверные данные об изменении лесистости и объемов заготовки древесины с середины XIX в. и до настоящего времени. За предыдущее время аналогичные показатели получены расчетным путем. Описана система управления лесным хозяйством за последние 200 лет. Отмечено, что в Беларуси существует центральный орган управления лесным хозяйством. Показано, что управление лесным хозяйством эволюционировало в сторону лесопользования и переработки древесины. В статье изложены современные подходы к устойчивому развитию лесного хозяйства. Описана роль лесов в сохранении экологических функций леса. Подчеркнуто значение депонирования диоксида углерода. Установлено, что Беларусь является источником депонирования углерода в объеме 24 млн т. Предлагается в перспективе перейти к финансированию лесного хозяйства на рентной основе, рассчитывая лесную ренту от величины конечной продукции леса с учетом необходимых переделов при нормативной рентабельности.

Ключевые слова: устойчивое развитие, лесопользование, управление лесами, лесистость территории, депонирование углерода, экологизация лесопользования.

Для цитирования: Лапицкая О. В. Особенности лесопользования Республики Беларусь в системе устойчивого развития // Труды БГТУ. Сер. 5, Экономика и управление. 2021. № 2 (250). C. 69-75.

\section{O. V. Lapitskaya \\ Sukhoi State Technical University of Gomel \\ FEATURES OF FOREST USE OF THE REPUBLIC OF BELARUS IN THE SYSTEM OF SUSTAINABLE DEVELOPMENT}

It is shown that the system of forestry management in Belarus has been developing since the 15 th century. In the Middle Ages, the main resources of the forest were considered products obtained from hunting and bee-keeping. It is noted that organized forestry in Belarus appeared later than in Western Europe, but earlier than in Russia. Wood as the main resource of the forest began to dominate since the end of the 18th century. The felling of timber led to a decrease in the forest cover of the territory of Belarus to $33 \%$ in 1913, and to $22 \%$ in 1918 . The work provides reliable data on changes in forest cover and volumes of timber harvesting from the middle of the 19th century to the present. For the previous time, similar indicators were obtained by calculation. The system of forestry management for the last 200 years is described. It was noted that in Belarus there is a central forestry management body. It is shown that forestry management has evolved towards forest use and wood processing. The article outlines modern approaches to sustainable development of forestry. The role of forests in preserving the ecological functions of the forest is described. The importance of carbon dioxide deposition is underlined. It was noted that Belarus is a source of carbon sequestration in the amount of 24 million tons. In the future, it is proposed to switch to financing forestry on a rent basis, calculating forest rent from the value of the final forest production, taking into account the necessary redistributions with standard profitability.

Key words: sustainable development, forest use, forest management, forest cover of the territory, carbon deposition, ecologization of forest management.

For citation: Lapitskaya O. V. Features of forest use of the Republic of Belarus in the system of sustainable development. Proceedings of BSTU, issue 5, Economics and Management, 2021, no. 2 (250), pp. 69-75 (In Russian). 
Введение. Лесопользование является завершающим звеном в системе лесовыращивания. Основную продукцию лесного хозяйства (древесину) мы получаем в процессе лесопользования. В то же время понятие лесопользования в настоящее время значительно расширено. В узком смысле слова лесопользование предполагает получение древесины от рубок главного и промежуточного пользования [1]. Современное понятие «лесопользование» включает получение от леса всех его ресурсов и полезностей. Под последними мы понимаем широкое использование недревесной продукции леса и экологических функций лесных насаждений [2]. Именно с этих позиций мы должны изучать лесопользование в условиях устойчивого развития.

Экологические полезности леса в настоящее время рассматриваются как равноправная составляющая лесопользования, что связано с глобальным изменением климата, а в ряде публикаций их значение даже выше, чем использование древесных ресурсов [3-6]. Учитывая глобальные угрозы для всего населения Земли, известное Парижское соглашение объявило стратегической задачей нашего времени удержание глобального потепления на уровне ниже $2^{\circ} \mathrm{C}[7,8]$. В то же время в литературе высказываются опасения, что это требование не будет выдержано из-за огромной стоимости мероприятий, которые необходимо провести (свыше 100 млрд долл. США ежегодно) [9]. Поэтому переход к устойчивому управлению лесами и экологизированному лесопользованию представляет собой сложную проблему в силу длительности процесса воспроизводства лесов и преобладания текущих проблем над перспективными потребностями [10].

Потребности народного хозяйства Беларуси в настоящее время требуют значительно увеличить отдачу от такого ценного природного возобновляемого ресурса, как лес. Эта отдача может быть повышена только путем глубокой переработки древесины и выходом на рынок таких товаров, как мебель, столярные изделия, фанера, целлюлоза и бумага.

В последние годы в связи с проблемой потепления климата, увеличения загрязнения атмосферы сернистыми соединениями резко возросло потребление биологического топлива. Поскольку биологическое топливо ранее было неконкурентоспособным по отношению к нефти и газу, в Европе была разработана система преференций для расширения использования биотоплива. В этом вопросе есть неоднозначное мнение: сторонники традиционных видов топлива доказывают правомерность использования ископаемых энергоресурсов, опасаясь конкуренции со стороны производителей биотоплива.
Однако сегодня преобладает точка зрения, согласно которой биотопливо является предпочтительным.

В понятие «биотопливо» входят различные органические продукты, но главная роль здесь отводится древесине. Древесное топливо в последние годы используется не как традиционные дрова, хотя и это имеет место, но потребляется в виде пеллет и древесной щепы.

Устойчивое лесопользование имеет целью получить не только максимальное количество древесины, но и обеспечить оптимизацию депонирования углерода лесами планеты. В последние годы здесь появились большие проблемы. Дело в том, что в ряде стран, особенно в России, существенно замедлился прирост лесов. В результате леса стали источником эмиссии углерода, а не его депонирования. В средствах массовой информации появились сообщения, что в силу этого России грозит уплата экологического налога до 50 млрд евро при экспорте своих товаров различного назначения в Европу.

Беларусь в этом отношении находится пока в значительно лучшем положении. Но в перспективе такая угроза может появиться и у нас.

Поэтому представляется актуальным рассмотреть лесные отношения в системе устойчивого лесопользования как в историческом разрезе, так и его современное состояние и перспективы.

Материалы и методика. Материалом для наших исследований послужили открытые ведомственные данные о заготовке и потреблении древесины Беларуси и сопредельных стран, а также литературные источники последних десяти лет белорусских и зарубежных авторов, которые приведены в списке литературы.

Методика исследований включала использование общепринятых методических подходов по вопросам экономики лесного хозяйства, лесоустройства, лесоводства и лесной таксации. Использовались также методы системного анализа, биометрии и математического моделирования $[11,12]$.

Основная часть. Лесная продукция и лесные полезности (функции) с древних времен и до настоящего времени имеют важное экономическое и экологическое значение. Рассматривать лесные отношения будем в соответствии с общими законами диалектики, т. е. в историческом разрезе, показывая эволюцию его развития.

Существующая система управления лесным хозяйством и лесопользования имеет длительную историю развития. Она возникла с появлением самого лесного хозяйства, которое возникло тогда, когда появились проблемы в организации лесопользования и понадобилось охранять леса.

Уже первые государства, возникшие на территории Беларуси, планировали проводить 
организованное лесопользование. Но продукция леса существенно отличалась от тех главных ресурсов и полезностей, которые используют сегодня.

М. Н. Карамзин в своей «Истории государства Российского», описывая период княжения Ярослава Мудрого (1019-1054), пишет, что князь в своей «Русской правде» отмечает необходимость оплаты штрафов за те или иные нарушения, которые совершены в лесу. При этом наибольшую ценность представляли звери и бортные деревья. Так, за бобра, украденного из норы, полагалось 12 гривен пени. Это была очень высокая стоимость. Для сравнения за украденного княжеского коня уплачивалось 3 гривны пени, а за простого - 2 гривны пени. Высокие штрафы вносились и за повреждения бортных знаков или уничтожение бортных деревьев. Здесь мы видим, что экономические отношения «лес - человек» распространялись пока только на продукцию охоты и пчеловодства. Сама древесина серьезного экономического значения не имела, хотя изделия из нее уже продавались. Все это формировало у населения (древлян, родимичей, дреговичей) отношение к лесу как к бесплатной кладовой древесины, но удерживало их от неразрешенной охоты.

Вскоре появляются сведения о регулировании пользования древесиной. Впервые это можно было прочитать в 1209 г. в известной «Русской правде». Там, наряду с крупными штрафами за нарушение прав охоты, бортничества, полагались и штрафные санкции за незаконную порубку деревьев. Но штраф за срубленное дерево был в 4 раза ниже, чем за несанкционированный отлов бобра или уничтожение борти. Это говорит о том, что древесина в силу наличия большого количества леса и редкого населения не была дефицитным продуктом, а борти и некоторые звери уже представляли значительную ценность. Хотя полезностями леса люди тоже пользовались, но об их возможном недостатке даже не подозревали. На том этапе лес был природным, а не хозяйственным и соответствовал своим функциям как большая и сложная биологическая система.

Значение древесины постепенно возрастало с увеличением народонаселения, уменьшением площадей лесов и все повышающимися потребностями людей. То, что древесина к XV-XVI вв. стала важным ресурсом, подтверждают документы того времени: Устав великого князя Великого Княжества Литовского (ВКЛ) Казимира Ягайловича (1492 г.), а также «Устава на волоки» (1557 г.) и «Устава и инструкция господарским лесничим» (1567 г.) великого князя ВКЛ и короля польского Сигизмунда Августа II, которыми регулировалось лесопользование и предусматривались меры наказания за незаконную порубку лесов [13].

Начало лесного хозяйства в Беларуси относится к 1557 г. Таким образом, организованное лесное хозяйство появилось у нас, хотя и несколько позже, чем в Западной Европе (например, во Франции это случилось в XIV в.), но почти на 150 лет раньше, чем в России. Здесь нет ничего удивительного. Организованное лесное хозяйство возникло раньше там, где было больше населения и меньше леса.

Положение с использованием лесных ресурсов и особенно с заготовкой древесины постепенно усложнялось, но вплоть до XIX и середины XX в. лесозаготовки и добыча других лесных ресурсов велись в естественном лесу.

Система управления лесами и лесным хозяйством за все время ее существования постоянно изменялась. Отметим, что лесное хозяйство до недавнего времени не было самостоятельным ведомством на уровне министерства. Хотя в России в конце XVIII в. и был организован лесной департамент, но он входил в состав разных министерств: финансов, государственных имуществ. Не следует забывать, что леса представляют собой ценный ресурс. Долгое время его рассматривают как бесплатный дар природы. Это приводит к желанию получить легкий доход от использования продукции леса, в основном древесины. Поэтому разные ведомства старались иметь леса в своем подчинении. Правда, в последние 100-150 лет появились ограничительные законы и правила, препятствующие безоглядному расхищению лесных ресурсов. Тем не менее владение этим ресурсом давало ведомству ряд преимуществ.

В советское время леса долго находились в подчинении лесозаготовителей. Это было оправдано существующей парадигмой лесного хозяйства - обеспечивать лесную промышленность древесиной в неограниченных объемах. Мощности леспромхозов рассчитывались, исходя только из пропускной возможности лесных дорог.

Результатом нахождения лесного хозяйства в других ведомствах явилось постоянное снижение лесистости на территории Беларуси. Желание воспользоваться лесным ресурсом в неограниченном количестве привело к сокращению лесистости в пределах Беларуси с 41\% в 1860 г. до $33 \%$ в 1913 г. и до 22\% в 1918 г.

В советское время началось интенсивное восстановление лесов и лесистость увеличилась к 1940 г. до 30\%. Результатом Великой Отечественной войны стало резкое снижение лесистости, в 1944 г. была зафиксирована самая низкая лесистость за всю историю - 18\% [14]. Усилиями лесоводов к настоящему времени лесистость доведена почти до 40\% (таблица). 
Лесистость и объемы заготовки древесины на территории Беларуси

\begin{tabular}{|c|c|c|c|}
\hline Годы & Лесистость, \% & $\begin{array}{c}\text { Рассчитанный среднегодовой } \\
\text { объем лесопользования, млн м }\end{array}$ & $\begin{array}{c}\text { Имеющиеся статистические } \\
\text { данные об объемах заготовки } \\
\text { по всем видам пользования, } \\
\text { млн м }\end{array}$ \\
\hline 1000 & $65-75$ & - & 0,3 \\
\hline 1100 & $65-75$ & - & 0,4 \\
\hline 1200 & $65-70$ & - & 0,5 \\
\hline 1300 & $60-70$ & - & 0,7 \\
\hline 1400 & $60-65$ & - & 1 \\
\hline 1500 & $60-65$ & - & 4 \\
\hline 1600 & $58-62$ & - & 4 \\
\hline 1700 & $55-60$ & - & 10 \\
\hline 1800 & $45-50$ & - & 12 \\
\hline 1860 & 44 & - & 16 \\
\hline 1900 & 37 & 6,5 & 20 \\
\hline 1913 & 33 & 7 & 28 \\
\hline 1918 & 22 & - & 33 \\
\hline 1936 & 27 & 18 & 34 \\
\hline 1940 & 30 & 19 & 36 \\
\hline 1944 & 18 & 10 & 26 \\
\hline 1955 & 31 & 8 & 13 \\
\hline 1975 & 34 & 10 & 12 \\
\hline 1985 & 34 & 11 & 10 \\
\hline 1992 & 34 & 10 & 12 \\
\hline 2001 & 38 & 12 & 14 \\
\hline 2005 & 38 & 14 & 21,21 \\
\hline 2010 & 38,5 & 14,5 & \\
\hline 2020 & 39,9 & 21,21 & \\
\hline & & & \\
\hline
\end{tabular}

Из таблицы видно, что лесопользование в довоенное время достигало 18-19 млн м³. В отдельные годы периода 1930-1939 гг. лесопользование доходило до 25 млн м ${ }^{3}[1]$.

Нельзя забывать, что территория Беларуси в то время составляла около $60 \%$ от нынешней площади, а лесопользование велось в основном в виде проведения рубок главного пользования.

Можно считать, что в этот период в Беларуси велось истощительное лесопользование. Оно продолжилось и в годы войны и до конца 50-х гг. ХХ в.

Экологические полезности леса в эти годы тоже использовались, но существенного влияния на хозяйственную деятельность в силу экономических и политических причин они не оказывали.

Во второй половине $30-\mathrm{x}$ гг. ХХ в. пришло осознание необходимости сохранять экологические полезности леса и не позволить истребить их в наиболее густонаселенных районах. Поэтому была выделена водоохранная зона. В основном это леса в Европейской части СССР. Исключением были леса Севера и части Урала. Для управления этими лесами создали специальный орган - Главлесоохрану.
После войны в СССР и ряде союзных республик, где имелось много лесных земель, были сформированы специальные министерства. Правда, просуществовали они недолго и вошли в состав разных ведомств, в основном в сельское хозяйство.

К концу 50-х и особенно в $60-$ - гг. ХХ в. во3никла необходимость в смене парадигмы лесного хозяйства. Если раньше главной целью лесного хозяйства была поставка древесины лесной промышленности для общесоюзного и республиканского потребления, то теперь возникла проблема поставки древесины на местном уровне: населению, школам, колхозам и т. д.

Лесное хозяйство, которое финансировалось из бюджета, не было обеспечено достаточным количеством техники и квалифицированных кадров. Здесь требовалось срочное исправление положения. Поэтому с 60-х гг. начала постепенно изменяться парадигма лесного хозяйства, оно стало приобретать бо́льшую хозяйственную самостоятельность за счет увеличения размеров промежуточного пользования и развития хозрасчета. Это позволило обеспечить потребность в древесине на местном уровне и резко сократило объем несанкционированных рубок леса [15]. 
Логически вытекающим из этого обстоятельства стало решение правительства Беларуси о создании в 1958 г. Главного управления лесного хозяйства при Совете Министров БССР. В 1965 г. было образовано Министерство лесного хозяйства. Но попытки взять под свой контроль леса не оставлялись как в России, так и в Беларуси. В России в 70-х гг. и позже лесное хозяйство снова объединили с Министерством лесной промышленности. Это привело к значительному ухудшению в управлении лесами и их деградации. Были вырублены хвойные леса Карелии и в нечерноземной части России. Возникла проблема перестойных мягколиственных лесов.

В Беларуси лесное хозяйство сохраняло самостоятельность. Это обеспечила твердая позиция руководства отрасли, поддержанная наукой. Результатом этих действий стало то, что уровень ведения хозяйства в Беларуси оказался намного выше, чем в России. В то же время и леса Беларуси были сильно истощены в советское время. Несмотря на увеличение лесистости, вырубка спелых лесов продолжалась с возрастающей интенсивностью. В СССР был постоянный дефицит древесины, особенно для Украины и южных районов. Поэтому требовалось постоянно увеличивать расчетную лесосеку вопреки научным расчетам. В 70-х гг. прошлого века в Беларуси несколько лет разрешали рубить приспевающие древостои, правда, в пределах разрешенных лимитов. К моменту распада СССР в Беларуси почти не осталось спелых лесов. По хвойным их было менее $2 \%$.

Лесная промышленность постоянно желала забрать лесное хозяйство под свой контроль. Кроме того, постоянно предлагалось снизить возраст рубки. За последние 30 лет существования СССР ученые и практики лесного хозяйства БССР несколько раз отбивали такие притязания. Претензии лесной промышленности продолжались и в независимой Беларуси, но без успеха. Отрасль сохранила свою самостоятельность. В последние месяцы снова возникла дискуссия о слиянии лесного хозяйства и концерна «Беллесбумпром». Но сейчас это предложение, похоже, не проходит.

Таким образом, мы видим, что система управления лесопользования совершенствовалась в интересах сбалансированного развития экономики народного хозяйства Беларуси. Ускоренное развитие хозрасчетных цехов в лесхозах обеспечило потребности на местном уровне в продуктах переработки древесины (пиломатериалы, столярные, кровельные изделия и т. д.). Усиленно развивался экспорт древесины и продукции из нее, но в экспорте преобладал крупный лес (пиловочник и баланс).
За последние годы лесхозы Беларуси существенно изменили структуру экспорта. В 2018 г. был запрещен экспорт круглого леса. Сделана попытка изменить положение, так как из нашей древесины к нам же завозилась мебель и другие изделия. Резко увеличился экспорт пиломатериалов. Потребность в Европе и Беларуси в топливной древесине привела к строительству заводов по производству пеллет и щепы. В 2021 г. заводов по производству пеллет будет уже порядка 14.

Министерство лесного хозяйства обеспечило в 2020 г. экспорт изделий из древесины на сумму 70 млн долл. США. В перспективе эта величина должна существенно возрасти.

Экологические полезности леса были важны для хозяйства и населения Беларуси всегда. В средние века лес как угодья (охотничьи, пастбища и т. д.) имел даже большее значение, чем как источник древесины. Вопросы водоохранных лесов возникали уже во времена Петра I. В настоящее время экологические полезности леса, по мнению ряда ученых, превышают его значения как источника древесины. На сегодняшний день в связи с ростом концентрации $\mathrm{CO}_{2}$, ведущего к глобальному потеплению климата, основной экологической полезностью леса является депонирование лесами диоксида углерода. Поэтому лесные отношения в общей системе природопользования все больше склоняются к экологизации лесного хозяйства и лесопользования. При этом, хотя в настоящее время основным источником существования лесного хозяйства является заготовка и переработка древесины (лесопиление, пеллеты и т. д.), экологизация природопользования требует изменения системы управления и финансирования лесным хозяйством, т. е. наметился переход на то, что лесное хозяйство должно получать основной доход от рентных платежей, где составной частью выступают экологические полезности [3].

Современные требования экономики и экологии приводят к тому, что экологические полезности в настоящее время постепенно переходят в разряд ресурсов. Так, за ежегодное депонирование углерода лесами Беларуси (около 24 млн т) при цене за 1 т депонированного углерода на рынке углеродных квот от 2 до 10 долл. США мы имеем потенциальную возможность получить значительные суммы в бюджет Беларуси.

Все это должно привести к тому, что финансирование лесного хозяйства должно постепенно переходить от получения доходов от реализации древесины и продукции из нее на рентную основу. При этом рента должна исчисляться от величины конечной продукции леса с учетом необходимых переделов для получения этой продукции и нормативной прибыли. 
В этом случае основной целью лесного хозяйства станет не заготовка и переработка древесины (с этим успешно справятся и другие ведомства), а целевое выращивание лесов с учетом оптимизации породного, возрастного состава и полноты.

Заключение. Обобщая вышеизложенное, приходим к выводу, что в условиях устойчивого развития лесные отношения постепенно должны переходить от приоритета заготовки и переработки древесины к максимизации выращивания лесных запасов и достижения наибольшей экономической и экологической эффективности от растущих лесов. Это потребует сохранения целостной структуры управления лесным хозяйством и продолжения целенаправленной подготовки высококвалифицированных специалистов лесного хозяйства.

\section{Список литературы} $367 \mathrm{c}$.

1. Багинский В. Ф., Есимчик Л. Д. Лесопользование в Беларуси. Минск: Беларуская навука, 1996.

2. Комплексная продуктивность земель лесного фонда / В. Ф. Багинский [и др.]. Гомель: ГГУ им. Ф. Скорины, 2007. 295 с.

3. Неверов А. В. Экономика природопользования. Минск: БГТУ, 2009. 554 с.

4. Шимова О. С. Эколого-экономические приоритеты устойчивого развития // Европа - наш общий дом. Экологические аспекты: тем. докл. Междунар. науч. конф., Минск, 6-9 дек. 1999 г.: в 2 ч. / НАН Беларуси. Минск, 2000. Ч. 1. С. 207-215.

5. Багинский В. Ф., Катков Н. Н., Лапицкая О. В. Проблемы и перспективы лесопользования в Республике Беларусь с учетом экологического императива // Научные основы устойчивого управления лесами: материалы Всерос. науч. конф., Москва, 15 сент. 2014 г. / Федеральное агенство научных организаций. М., 2014. С. 22-23.

6. Штейнбок А. Г. Леса и лесное хозяйство Беларуси как фактор экологической и социально-экономической устойчивости // Европа - наш общий дом. Экологические аспекты: тем. докл. Междунар. науч. конф., Минск, 6-9 дек. 1999 г.: в 2 ч. / НАН Беларуси. Минск, 2000. Ч. 1. С. 215.

7. Paris Agreement: Conference of the Parties Twentyfirst session. Paris, 30 Nov. to 11 Dec., 2015. URL: http://unfccc.int/resource/docs/2015/cop21/eng/109r01.pdf (date of access: 03.02.2021).

8. New Climate Economy / World Resources Institute, Washington, DC 20002. USA, 2014. 80 p.

9. The truth about climate change / R. Watson [et al.]. The Universal Ecol. Fund (FEU-US), 2016. 8 p. DOI: 978-0-9831909-1-2.

10. Observed forest sensitivity to climate implies large changes in 21st century North American forest growth / N. D. Charney [et al.] // Ecol. Letters. 2016. Vol. 19, no. 9. P. 1119-1128. DOI: 10.1111/ele.12650.

11. Багинский В. Ф., Лапицкая О. В. Биометрия в лесном хозяйстве. Гомель: ГГУ им. Ф. Скорины, 2017. $376 \mathrm{c}$.

12. Багинский В. Ф. Применение системного анализа в лесном хозяйстве. Гомель: ГГУ им. Ф. Скорины, 2016. 175 с.

13. Багинский В. Ф. История лесного хозяйства в Беларуси // Лес в жизни восточных славян от Киевской Руси до наших дней: сб. науч. тр. Гомель, 2008. Вып. 57. С. 64-70.

14. Багинский В. Ф. Лесистость Беларуси и перспективы ее увеличения // Проблемы лесоведения и лесоводства: сб. науч. тр. Гомель, 2003. Вып. 56. С. 176-180.

15. Багинский В. Ф. Необходимость смены парадигмы в лесном хозяйстве Республики Беларусь // Проблемы лесоведения и лесоводства: сб. науч. тр. Гомель, 1999. Вып. 50. С. 19-28.

\section{References}

1. Baginskiy V. F., Esimchik L. D. Lesopol'zovaniye v Belarusi [Forest management in Belarus]. Minsk, Belaruskaya navuka Publ., 1996. 367 p.

2. Baginskiy V. F., Esimchik L. D., Grimashevich V. V., Ermolina I. V., Lapitskaya O. V. Kompleksnaya produktivnost' zemel' lesnogo fonda [Integrated productivity of land Forest Fund]. Gomel, GGU imeni F. Skoriny Publ., 2007. 295 p.

3. Neverov A. V. Ekonomika prirodopol'zovaniya [Economics of Nature Management]. Minsk, BGTU Publ., 2009. 554 p.

4. Shimova O. S. Ecological and economic priorities for sustainable development. Tematicheskiye doklady Mezhdunarodnoy nauchnoy konferentsii "Evropa - nash obshchiy dom. Ekologicheskiye aspekty" [Thematic reports of the International scientific conference "Europe is our common home. Environmental aspects"]. Minsk, 2000, part 1, pp. 207-215 (In Russian).

5. Baginskiy V. F., Katkov N. N., Lapitskaya O. V. Problems and prospects of forest management in the Republic of Belarus, taking into account the environmental imperative. Materialy Vserossiyskoy nauchnoy 
konferentsii "Nauchnyye osnovy ustoychivogo upravleniya lesami" [Materials of the All-Russian Scientific Conference "Scientific basis for sustainable forest management"]. Moscow, 2014, pp. 22-23 (In Russian).

6. Shteynbok A. G. Forests and forestry in Belarus as a factor of environmental and socio-economic sustainability. Tematicheskiye doklady Mezhdunarodnoy nauchnoy konferentsii "Evropa - nash obshchiy dom. Ekologicheskiye aspekty" [Thematic reports of the International scientific conference "Europe is our common home. Environmental aspects"]. Minsk, 2000, part 1, p. 215 (In Russian).

7. Paris Agreement: Conference of the Parties Twentyfirst session. Paris, 30 Nov. to 11 Dec., 2015. Available at: http://unfccc.int/resource/docs/2015/cop21/eng/109r01.pdf (accessed 03.02.2021).

8. New Climate Economy. USA, 2014. 80 p.

9. Watson R., Carraro C., Canziani P., Nakicenovich N., McCarthy J. J., Goldemberg J., Hisas L. The truth about climate change. The Universal Ecol. Fund (FEU-US), 2016. 8 p. DOI: 978-0-9831909-1-2.

10. Charney N. D., Babst F., Poulter B., Record S., Trourt V. M., Frank D., Enquist B. J., Evans M. E. Observed forest sensitivity to climate implies large changes in 21st century North American forest growth. Ecol. Letters, 2016, vol. 19, no. 9, pp. 1119-1128. DOI: 10.1111/ele.12650.

11. Baginskiy V. F., Lapitskaya O. V. Biometriya v lesnom khozyaystve [Biometrics in Forestry]. Gomel, GGU imeni F. Skoriny Publ., 2017. 376 p.

12. Baginskiy V. F. Primeneniye sistemnogo analiza v lesnom khozyaystve [Application of system analysis in forestry]. Gomel, GGU imeni F. Skoriny Publ., 2016. 175 p.

13. Baginskiy V. F. History of forestry in Belarus. Les v zhizni vostochnykh slavyan ot Kiyevskoy Rusi do nashikh dney: sbornik nauchnykh trudov [Forest in the life of the Eastern Slavs from Kievan Rus to the present day: collection of scientific papers], 2008, vol. 57, pp. 64-70 (In Russian).

14. Baginskiy V. F. Forest cover in Belarus and prospects for its increase. Problemy lesovedeniya i lesovodstva: sbornik nauchnykh trudov [Problems of Forest and Forestry: collection of scientific papers], 2003, vol. 56, pp. 176-180 (In Russian).

15. Baginskiy V. F. The need to change the paradigm in forestry in the Republic of Belarus. Problemy lesovedeniya i lesovodstva: sbornik nauchnykh trudov [Problems of Forest and Forestry: collection of scientific papers], 1999, vol. 50, pp. 19-28 (In Russian).

\section{Информация об авторе}

Лапицкая Ольга Владимировна - кандидат экономических наук, доцент, доцент кафедры «Маркетинг и отраслевая экономика». Гомельский государственный технический университет имени П. О. Сухого (246746, г. Гомель, пр-т Октября, 48, Республика Беларусь). E-mail: Olapitskaya@mail.ru

\section{Information about the author}

Lapitskaya Olga Vladimirovna - PhD (Economics), Associate Professor, Assistant Professor, the Department of Marketing and Sectoral Economics. Sukhoi State Technical University of Gomel (48, Oktyabrya Ave., 246746, Gomel, Republic of Belarus). E-mail: Olapitskaya@mail.ru 